\title{
Behçet's disease: review with emphasis on dermatological aspects*
}

\author{
Maria Antonieta Rios Scherrer ${ }^{1}$ \\ Lucas Campos Garcia ${ }^{1}$
}

\author{
Vanessa Barreto Rocha ${ }^{1}$
}

DOI: http:/ / dx.doi.org/10.1590/abd1806-4841.20177359

\begin{abstract}
Behçet's disease is a systemic vasculitis characterized by attacks of acute inflammation, which can affect almost every vascularized area of the body. There is a close correlation between the geographical distribution of HLA-B51 and its prevalence. In the etiopathogenesis there are indications of genetic susceptibility associated with environmental influence. Among the involved genes are those that encompass innate and adaptive immunities. Polymorphisms and epistatic interactions in several genes are described, as well as the presence of imbalance lineage between HLA-B51 and A (MICA). Herpes simplex and Streptococcus sanguinis may be important extrinsic factors. An increase of Th1 response and of IL-21 is observed. The production of IL-21 is positively related to Th17 cells and negatively to T-regs. The mucocutaneous manifestations are Behcet's disease markers, and their earlier onset indicates a worse prognosis. Recurrent oral ulcers have varied sizes and arrangements, genital ulcers are recurrent, leaving scars, skin lesions are multivaried, and pathergy, although not so frequent, is important for the diagnosis. There are numerous attempts to validate indexes that can evaluate the disease activity and among them the Mucocutaneous Activity Index. This is a specific score that can help with therapeutic decisions and to reduce morbidity, but still lacks validation. The clinical manifestations of other organs are described as well as treatment options.
\end{abstract}

Keywords: Behçet syndrome; Diagnosis; Review literature as topic; Vasculitis

\section{INTRODUCTION}

Behçet's (BD) is a systemic vasculitis of unknown etiology, characterized by recurrent attacks of acute inflammation. The frequency and duration of these outbreaks are unpredictable and do not follow an identifiable pattern from the onset. As a systemic vasculitis, it can affect almost every vascularized area of the body. ${ }^{1}$

Described in 1937 by the Turkish dermatologist Hulusi Behçet as a triad that associated uveitis with oral and genital aphthosis, it had been known since the fifth century BC and its description can be found in the Hippocratic third book of endemic diseases. Since then, other manifestations have been described and added beside new aspects of epidemiology, immunopathogenesis, and treatment. ${ }^{1-4}$

\section{EPIDEMIOLOGY}

$\mathrm{BD}$ is very prevalent from the Mediterranean to Japan, in countries alongside the ancient Silk Road, $30^{\circ}-40^{\circ}$ north of the Equator (14-20/100,000 population). The highest BD prevalence ratios were found in Turkey and its incidence is rare in the West $(0.64 / 100,000$ population in the United Kingdom and 0.12 $0.33 / 100,000$ in the United States). There is a close correlation between the geographical distribution of the human leukocyte antigen (HLA) B51 and the prevalence of BD. The frequency of HLA-B51 in the Silk Road area is $20-25 \%$ among the general population and
$50-80 \%$ among patients. In Northeastern Europe and the United States, this frequency is $2-8 \%$ and $15 \%$, respectively. BD is less frequent among Japanese immigrants in the United States, especially in Hawaii, and among Turkish immigrants in Germany. Mahr et al., in France, showed that the prevalence of the disease among the suburban population in Paris was higher among immigrants from North Africa or with Asian ancestors than those from European origin, concluding that the risk of BD is not related to the immigrant's age and that the disease has a primarily hereditary basis. In contrast to these studies, two older publications suggested that Turkish immigrants in Germany had a higher prevalence of the disease than natives who did not emigrate, corroborating the environmental influence on its susceptibility. Although the subject remains controversial, the genetic influence is very strong, as it will be shown throughout this article. ${ }^{1,4}$

Although it is rare in Africa, two series of studies from 2007 to 2011 have been recently published, one in Nigeria and another in Dakar. In 2014, another group studied analyzed Azerbaijani subjects living in Iran. The incidence of BD declines from the South to the North, according to authors in Italy who also investigated its prevalence among patients of Italian and non-Italian origin living in these areas. Similar to other studies in France and Germany, the prevalence was higher among immigrants. A recent Dutch study in

Received on 11.06.2017.

Approved by the Advisory Board and accepted for publication on 11.07.2017.

* Work performed at the Dermatology Division at Hospital das Clínicas - Universidade Federal de Minas Gerais (UFMG) - Belo Horizonte (MG), Brazil Financial support: None

Conflict of interests: None

Contact Dermatitis Outpatient Clinic - Dermatology Division at the Hospital das Clínicas - Universidade Federal de Minas Gerais (UFMG) - Belo Horizonte (MG), Brazil

C2017 by Anais Brasileiros de Dermatologia 
patients with different ethnic origins living in the Rotterdam area showed a prevalence of $1 / 100,000$ population among Dutch Caucasians, 71/100,000 among Turks, and 39/100,000 among Moroccans, suggesting that the prevalence among Turks and Moroccans is the same as in their countries of origin. The study did not mention the generation of the affected immigrants. Therefore, more consistent studies with second and third generation patients are needed to evaluate the genetic and environmental importance in the pathogenesis of the disease. ${ }^{1,3-6}$

It is believed that $\mathrm{BD}$ affects more males than females, in a proportion that varies from 1.5-5:1, and is in general more serious in male patients. However, a series of western studies (which included Brazilian studies) revealed a female predominance, but with less intense manifestations. Factors that modulate this clinical expression are still unknown. ${ }^{3}$

In general, BD has a peak age of onset between 20-30 years, and patients who develop the disease from a very young age present with more severe forms, with more organs affected. However, that study did not show the severity or extent of the disease. ${ }^{6}$ On the other hand, another paper proposed that men with BD had a risk of involvement of vital organs even if they had only mucocutaneous manifestations at the onset of the disease. ${ }^{6}$ These data were confirmed by Italian and Turkish studies. ${ }^{6}$ A recent German meta-analysis has confirmed that male sex is more associated with ocular disease, papulo-pustular lesions, superficial and deep vein thromboses, whereas female sex has been associated with genital ulcers and joint involvement. ${ }^{6}$ Other meta-analyzes associated the male sex with heart disease and positive pathergy, while erythema nodosum was associated with females. ${ }^{6}$ In this way, it seems that gender influences the prognosis, and men have a worse evolution due to the frequency of vital organs affected. ${ }^{6}$

The pediatric population is also affected, and a study performed in the UK in 2016 showed that the frequency of having a first-degree relative also affected was 17\%. Regarding clinical manifestations, $56.5 \%$ of the patients showed gastrointestinal involvement and $28.3 \%$, central nervous system involvement. However, these data were not very well documented by means of complementary examinations. ${ }^{5}$

Positive skin pathergy test (SPT) results vary among geographic areas, with high sensitivity and specificity in patients from Turkey, some Mediterranean and Middle East countries, and Japan. ${ }^{4}$ However, current studies show a decline in this trend. ${ }^{4}$

\section{GENETICS}

Four aspects demonstrate the genetic influence on BD susceptibility: peculiar geographical distribution, familial aggregation, correlation with HLA-B51 class I antigen, and polymorphisms in genes that control immune responses. The association of BD with HLA-B5 (51) was first described by Ohno et al. in 1973. They demonstrated that HLA-B5 is heterogeneous in its composition, including HLA-B51 and HLA-B52. In the MHC locus, HLA-B51 and HLA-B5701 were associated with the pathogenesis of the disease, mainly among people from countries alongside the ancient Silk Road. Although associations with HLA-A and HLA-C have been described, they are non-specific and require confirmation. Other MHC genes are being investigated, in- cluding TNF and MHC class I genes (MICA), but the exact mechanism has not yet been determined. ${ }^{1}$

The association with HLA-B51 appears to be important in neutrophil activation. However, the presence of HLA-B51 alone is not sufficient to explain all the symptoms observed in BD. In this sense, several recent studies have been published involving multicentric groups from different geographic regions suggesting the involvement of other genes. A case series of Iranian patients showed association with HLA-B35, HLA-B51, HLA-B52, and HLA-Bw4. ${ }^{1}$

Supplementary studies suggest associations with HLA-B15, B27, B57, and A26. On the other hand, HLA-B49 and A03 appear to be protective. Other significant associations are IL-23R/IL12RB2, IL10, STAT-4, CCR1-CCR3, KLRC4, ERAP1, TNFAIP3, and FUT2 loci, in addition to other rare variants. These genes encompass innate and adaptive immunities, and confirm the Th1 versus Th2 polarization and the involvement of Th17 subsets. ${ }^{5,6}$

Some studies have been directed to the research of single nucleotide polymorphisms (SNPs) and others to epistatic interactions with endoplasmic reticulum associated aminopeptidase 1 (ERAP-1). A significant genetic association was found with SNP rs116799036, suggesting that this SNP - which is located in the HLA-B region between HLA-B and the MICA genes - is responsible for the relationship between HLA-B51 and BD. The association and interaction of ERAP-1 and HLA-B has also been consistent. Many other associations have been described: chromosomes 6 and 18 with IL-12A and SNP rs7810546 at chromosome 3. CC homozygous genotypes and C allele polymorphism of rs2910164 are protective factors against BD, but rs3746444 and rs28362491 polymorphisms of miRNA-499 and of the promoter NFKB1 are involved in genetic susceptibility to the disease. The Iranian group suggested that the robust association of HLA-B/MICA can be explained by the presence of a single rs76546355 variant between them. ${ }^{4-6}$

The unifying concept of "MHC-I-opathy" has been proposed, suggesting that spondyloarthritis, psoriasis, and BD share clinical findings due to contact points of the body with the external environment (oral mucosa, intestine, skin) or places subject to physical stress, such as entheses, including those of the eyes, vascular walls, and valve regions. It seems that the link between these diseases would be in their associations with MHC class I alleles such as B51, C0602, B27, and ERAP-1. ${ }^{6.7}$

Another study has shown that the expression of suppressor of cytokine signaling proteins (SOCS) - as it negatively regulates the cytokine JAK-STAT signaling pathway - affects the production of IFN-gamma, IL-12, IL-23, IL-6 SOCS1, and 3mRNA. These cytokines were greatly increased in the peripheral blood mononuclear cells of BD patients compared to the control group. The authors concluded that SOCS expression was unbalanced in BD patients when compared to controls, and also in patients with systemic involvement when compared to those with mucocutaneous involvement. ${ }^{5}$

Studies conducted in Turkey and Japan reported an association between SNPs in IL-10 and IL-23R/IL-12RB2 genes with BD. Disease-related variants were located more on the IL-23R side than on IL-12RB2. IL-23 and IL-12 share p40 as an alpha-receptor subunit, which acts to induce T-cell activation to produce IL-17, one of the major pathways of activation of T helper 17 (Th-17) cells. ${ }^{4}$ 
Associations with Toll-like receptors 7 (TLR7) and other nucleic acid sensing genes of innate immunity-like inflammatory pathways such as IFI16 (a dsDNA cytosolic sensor and mediator of the AIM2 dependent inflammatory pathway) appear to influence BD susceptibility. Analyzes indicated that polymorphisms of REL rs842647 are associated with patients with cutaneous lesions. In addition, the micro RNA signature of peripheral blood mononuclear cells (miR-199-p3 and miR-720) appears to be important in regulating the activation of innate immunity and $\mathrm{T}$ cell function. ${ }^{5}$

A Chinese study showed that polymorphisms of the nitric oxide synthase gene, such as NOS3/rs1799983, were associated with the disease, and the involvement of CD16 and CD11c was associated with its susceptibility. They also confirmed the connection of CIITA/rs12932187 and NOD/rs2075818 to BD, and evaluated the modulatory factors of the TLR signaling pathway. Two SNPs near IRF8 were associated with the disease. ${ }^{5}$

A meta-analysis of 8 studies analyzing 2538 patients and 2792 healthy controls showed mutations in the familial Mediterranean fever (MEFV) gene. ${ }^{5}$

Research on genes related to apoptosis have not shown conclusive results. Other epigenetic searches with inverted repeat sequences (IRS) have shown that the methylation level of IRS elements may contribute to the pathogenesis of the disease. ${ }^{5}$

Several other studies on MHC locus genes including TNF genes, miRNA, and other polymorphisms are underway or have already been published. Some of them are relevant, but others are not. Three meta-analyzes reaffirmed the presence of lineage imbalance with HLA-B51 and A (MICA), and the association with BD susceptibility in the MICA-TM A6 allele, especially among Europeans and Asians. However, much research is still needed to better elucidate the genetic landscape involved, which is complex. ${ }^{5}$

\section{PATHOGENESIS}

Several aspects indicate an interaction between innate, adaptive, and environmental immunity in the development of the disease, which would arise in the appropriate genetic field as previously discussed.

Bacterial and viral infectious agents have been investigated, but without conclusive results. For example, it is suspected that herpesvirus and Streptococcus sanguinis could be important extrinsic factors. In addition, the bacterial plaque ecology and the immune response to these microorganisms may be affected in $\mathrm{BD}$, leading to changes seen in the oral mucosa. ${ }^{5}$ Studies have shown that improvement in oral health leads to improved prognosis. Coit et al. evaluated the salivary microbioma, observing that patients presented with a microbial structure less diverse than healthy controls, with Hemophilus parainfluenza more abundant than Alloprevotella rava and Leptotrichia. $^{4-6}$

Recent studies have shown peculiar dysbiosis of the gut microbiota with a significant reduction of butyrate production in $\mathrm{BD}$ patients. Butyrate is able to promote the differentiation of regulatory T cells (T-reg), and thus, its decrease would lead both to the reduction of T-reg cell response and to the activation of immunopathological $\mathrm{T}$ cell effector responses. Other studies have shown predisposition to insulin resistance and metabolic syndrome in patients, and reduction of angiopoietin 1 especially in those with vascular involvement. ${ }^{6}$

Research into a specific antigen for the disease has been frequent, and a Chinese group demonstrated high IgG reactivity to an endothelial cell autoantigen. ${ }^{5}$

Matzinger proposed the danger model, developed by a continuous autoimmune cascade resulting from signals emitted by the host's affected cells. This immune reaction would override the external stimulus. T cells and other antigen-presenting cells (APC) would command the process, which would be perpetuated on a favorable genetic terrain. Damage by a non-self entity would trigger permanent aggression by activating an uncontrolled adaptive response. Because of their similarity to other pathogenic proteins, heat shock proteins (HSP60) could be involved. This adaptive reaction to external stimuli would persist in the permanent pathogenic presence via autoantigens that would activate dendritic T cells and B cells. ${ }^{1}$

Thus, overexpression of proinflammatory cytokines - especially Th1 and Th17 and probably associated with genetic susceptibility - seems to be responsible for the increased inflammatory reaction in $\mathrm{BD}$. Stimulated lymphocytes would activate neutrophils and endothelial cells, and HSPs would probably trigger innate and adaptive immune responses. Hypersensitivity to Streptococcus sanguinis is observed through the innate immune system. Microbial flora along with stress proteins in oral and periodontal mucosal tissues could cross react with host tissues and also stimulate the proliferation of autoreactive T cell clones. HSPs would transfer antigenic peptides to APCs that could be identified by Toll-like receptors (TLRs), triggering an endogenous signal of danger that would lead to the activation of innate and adaptive immune systems. They could also, directly or indirectly, lead to increased expression of vascular endothelial growth factor by T cells, causing both endothelial cell damage and vasculitis. Cohen proposed that TLRs and IL-1, IL18 , and IL-33 receptors would play an important role in maintaining the state of hyperactivation that would provoke the inflammatory changes observed. Many studies have shown that patients' peripheral blood contains IFN-gamma and IL-12 suggesting involvement of TH1 cells. Increased IL-1, IL-6, IL-18, TNF-alpha, and chemokines would reflect the activation of innate and adaptive immune systems. Neutrophils are hyperactivated with increased phagocytosis, superoxide production, increased chemotaxis, and lysosomal enzyme production. Lymphocytes, in turn, exhibit abnormal functions such as clonal expansion of autoreactive T cells specific for HSP60 peptides. In addition, gamma-delta $\mathrm{T}$ cells are more prevalent in the blood and mucosal lesions of patients. In conclusion, it seems that the interaction between T cells, neutrophils, and APCs would contribute to the pathogenesis of BD. ${ }^{1}$

Increased Th1 and IL-21 and reduced expression of FoxP3 in CD4+ cells have been reported in patients with active disease. This production of IL-21 is positively related to Th17 cells and negatively related to T-regs. In addition, IL-21 appears to be induced only by IL-6. On the other hand, there are indications that IL-21 has an autocrine regulatory system. Activated Th naive cells differentiate into Th17 cells in the presence of IL-21. Other studies show that IL-21 has effects on B cell differentiation, plasma cell generation, and on the activation of the JAK-STAT pathway. The reduction of T-regs in BD 
suppresses antigen-specific T cell responses. ${ }^{1}$

The pathogenesis of pathergy phenomenon is also not well understood. It is known that skin micropuncture tests provoke reactions even in healthy individual as a cutaneous vascular axon reflex. These reactions promote the release of inflammatory mediators by the traumatized cells, along with a series of events that compete for the process of wound repair. In BD patients with pathergy reactions, these events are abnormal and increased, that happens in a scenario of sterile, nonmicrobial inflammation. Injury caused by the needle is suspected to trigger a marked skin inflammatory response with cytokine release by keratinocytes and other cells of the epidermis and dermis, resulting in a vascular infiltrate observed in cutaneous biopsies. ${ }^{1,46,8}$

\section{MUCOCUTANEOUS MANIFESTATIONS}

Mucocutaneous manifestations are markers of $\mathrm{BD}$ and their recognition may allow diagnosis and treatment. ${ }^{1}$ The earlier the onset of manifestations, the worse the prognosis, with consequent increase in morbidity and mortality. ${ }^{1}$

Oral ulcers are present in almost all cases. These lesions are the initial manifestation in up to $80 \%$ of the patients and precede subsequent ones in an average of 7-8 years. They are painful ulcers with well-defined borders, erythematous halo. The formation of a yellowish or grayish pseudomembrane is also observed. They are classified by size and arrangement into minor $(<1 \mathrm{~cm})$, major, and herpetiform ulcers. They appear in outbreaks averaging 9.8 times a year, with minor ulcers lasting for 7-10 days and up to 4 weeks in cases of major ulcers. They are preferably located in the non-keratinized portions of the oral mucosa (Figures 1 and 2). They can leave scars and sequelae, such as dysphagia, odynophagia, and dyspnoea. Clinically, they are practically indistinguishable from recurrent oral aphthosis..$^{10}$ However, features that favor the diagnosis of BD include the number of ulcers $(>6)$, synchronous occurrence of more than one clinical variant, diffuse enanthem, and soft palate and oropharyngeal involvement. Rigorous clinical follow-up is the best resource for diagnostic elucidation. ${ }^{11}$

Genital ulcers, another classic manifestation, are similar to oral ulcers in appearance and course. However, they are less recurrent, have a greater tendency towards scar formation, and some exhibiting necrotic borders. Deeper lesions may complicate the onset of fistulas, especially in females. ${ }^{9}$ In men, the most affected site is the scrotum, but affected areas may include the foreskin, penis, glans, and, in some cases, the epididymis (Figures 3 and 4). In women, ulcers in the vagina and colon can be oligosymptomatic. The most frequently involved region is the major labia (Figure 5). ${ }^{11}$

Although cutaneous lesions are non-specific for $\mathrm{BD}$, they are essential for diagnosis. Their frequency varies from $48-88 \%$ in diagnosed patients. ${ }^{9}$ Cutaneous manifestations can be divided into papulopustular lesions, erythema nodosum lesions, thrombophlebitis, and varied cutaneous and vasculitic lesions. Initial lesions exhibit leukocytoclastic vasculitis or neutrophilic aggressions to vessels, while the mature ones are characterized by lymphocytic vasculitis.

Papulopustular lesions are the most prevalent and tend to be more frequent in individuals with positive response to a pathergy test or in those with joint involvement. ${ }^{4}$ They usually appear as papules that become pustules in $24-48$ hours. ${ }^{12}$ These lesions are sterile and may resemble folliculitis or have an acne-like appearance (Figures 6 and 7). The latter may be clinically and histopathologically indistinguishable from acne vulgaris. ${ }^{5}$ One clue to differentiation is the absence of comedones and marked involvement of the extremities. ${ }^{11}$ Poor response to classical therapies against acne, such as antibiotics, is another indicator. ${ }^{13}$

Erythema nodosum (EN) lesions occur in one-third of patients, typically affecting the lower limbs. Gluteal regions, the face and neck may also be affected. They do not evolve with ulceration and last between 2-3 weeks. Recurrence is common. ${ }^{11}$ It can be dis-

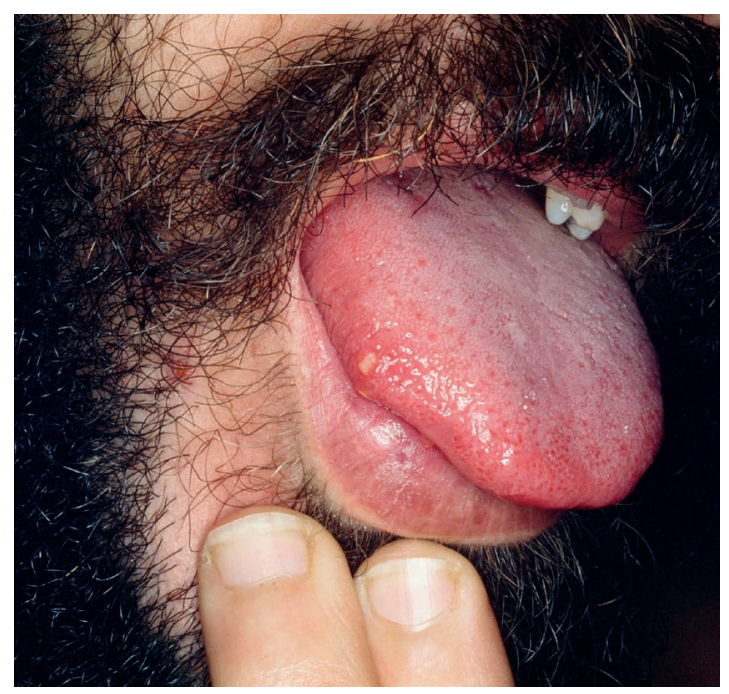

Figure 1: Aphthous ulceration on the tongue

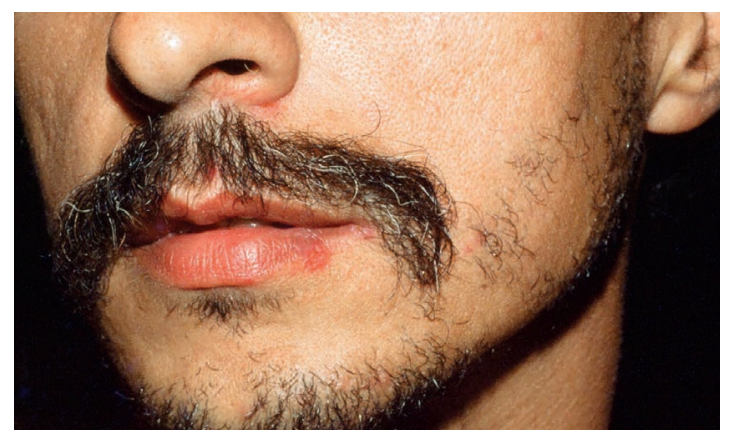

FIGURE 2: Ulcer on the lower lip

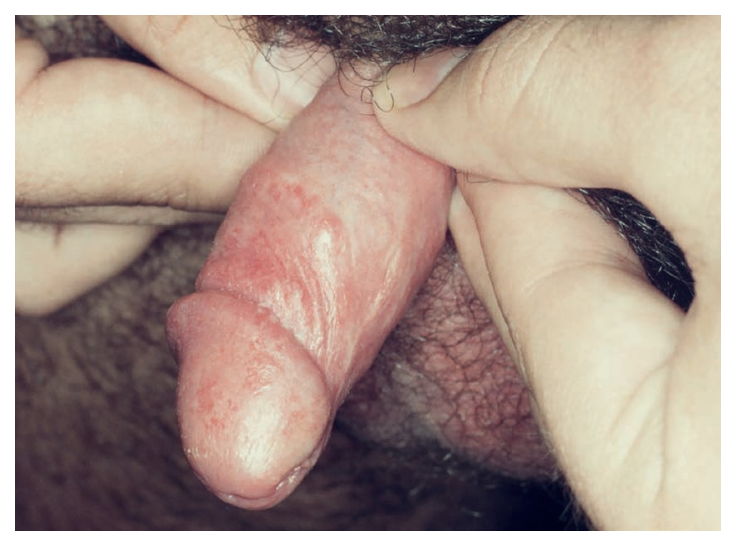

FigURE 3 : Small erosions grouped in the penile region 
tinguished from the classic EN lesions by the presence of vasculitis on histopathological examinations. ${ }^{14}$ They usually present with residual hyperpigmentation. ${ }^{1}$

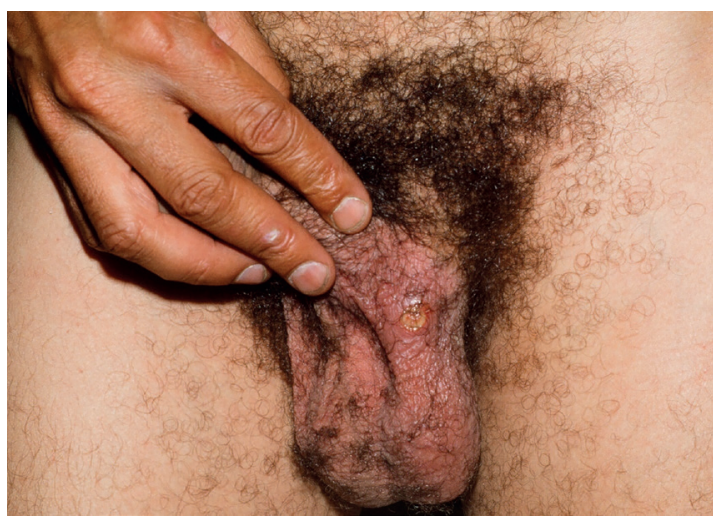

Figure 4: Ulcer in the scrotal area

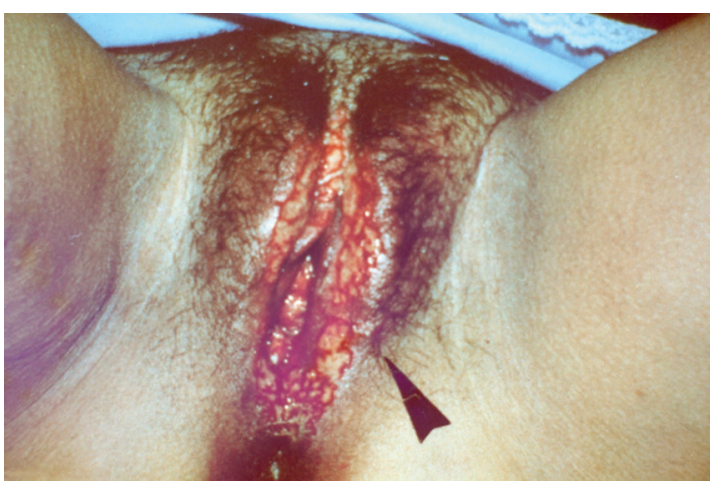

FigURE 5 : Ulcers in the labia majora

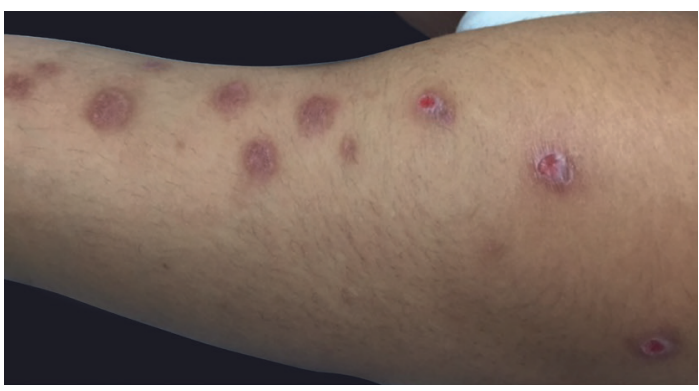

FIGURE 6: Excoriated and residual folliculitis-like lesions on the upper limb

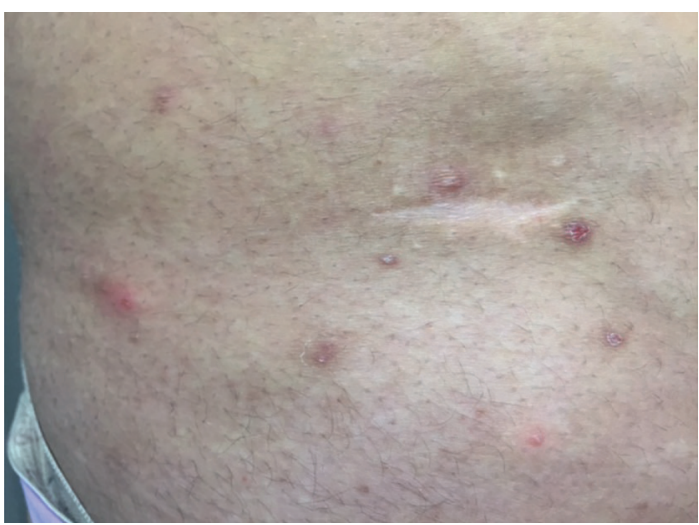

FIGURE 7 : Folliculitis-like lesions on the abdomen
Subcutaneous thrombophlebitis is often confused with EN lesions (Figure 8), ${ }^{8,11}$ It is characterized by tender erythematous nodules, sometimes showing a linear arrangement. The lesions may migrate daily depending on the affected vascular segment. They are important for being a marker of other vascular involvements. ${ }^{4,15}$

Cutaneous ulcers affect up to $3 \%$ of patients, are recurrent, and leave scars. They occur in several locations, such as legs, armpits, breasts, and interdigital and inguinal regions (Figure 9). According to some authors, they are the most specific cutaneous manifestation of BD. ${ }^{16}$ They are common in affected children. ${ }^{17}$ In this age

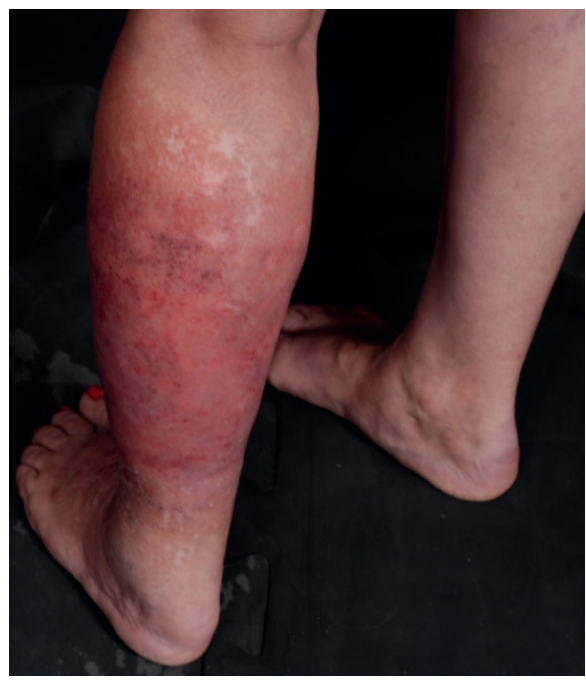

FIGURE 8 :

Thrombophlebitis-like lesion on the lower limb
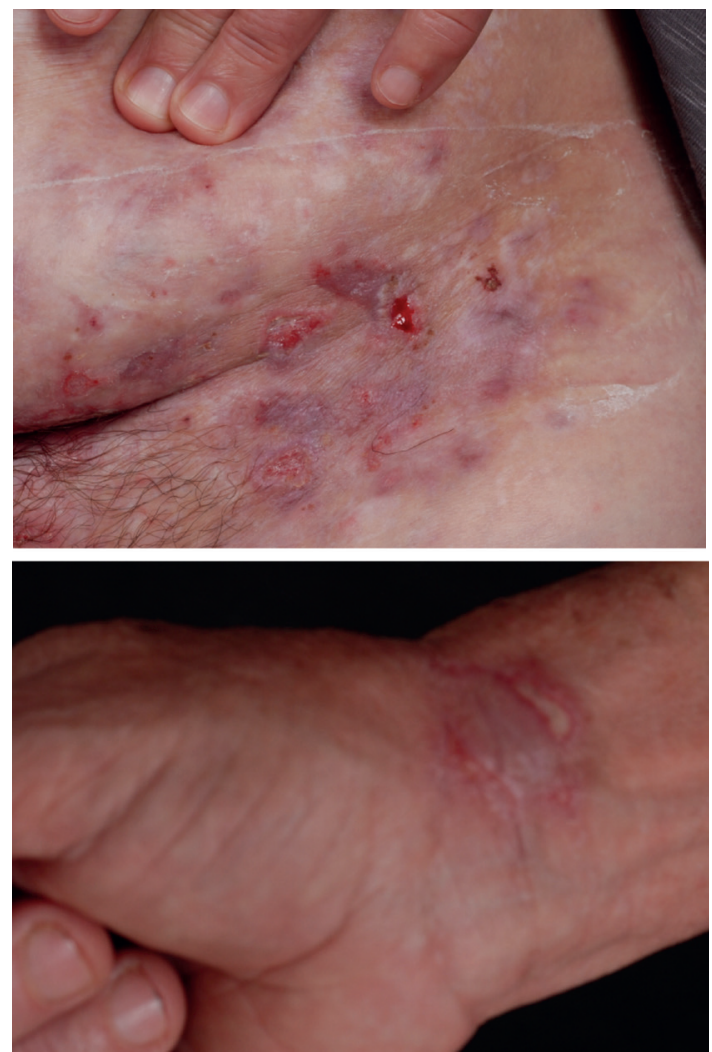

FIGURE 9: Ulcerations on the abdomen and wrist 
group, perianal ulcers and arthralgia are more frequent and a more serious clinical course of uveitis is also observed.

Vascular manifestations may appear as palpable purpura, subungual infarcts, or symptoms mimicking clinical pictures of diseases such as Sweet's syndrome, pyoderma gangrenosum, and erythema multiforme. ${ }^{11}$ In these cases, the presence of other signs of BD or presence of HLA-B51 may help differential diagnosis. ${ }^{18}$ In addition, Schreiner \& Jorizzo postulated that only lesions with neutrophilic vascular reaction or documented leukocytoclastic vasculitis can be attributed to BD. ${ }^{19}$

\section{PATHERGY REACTIONS}

Pathergy is defined as an altered state of the tissue response to a minimal needle puncture trauma, reflecting an exacerbated response of the innate immune system. ${ }^{8}$ The phenomenon was described in BD in 1937, and quickly became important for diagnosis.

Testing methodology may vary among institutions, but most studies applied a 20-26 G needle to perform 4-6 intradermal punctures at a $45^{\circ}$ angle in the flexor region of the forearm. This is the site of choice for having a higher positivity rate. ${ }^{8}$ The reading should be performed 48 hours after the procedure.

Pathergy lesions are clinically manifested as erythematous papules, sometimes topped by a sterile pustule (Figure 10). Classically, the test is considered positive when a reaction greater than $2 \mathrm{~mm}$ occurs. However, histopathological examinations may show typical alterations in small-diameter lesions. Dermoscopy may also be useful for evaluation (Figure 11). ${ }^{20}$

Histopathological examination reveals an inflammatory infiltrate with predominance of mononuclear cells around dermal vessels and an increase in the number of mast cells. Neutrophilic vasculitic reaction may also be present. ${ }^{8}$

Patients with a disease history of less than 5 years, those with HLA-B51, and cases without treatment tend to have a higher positivity rates. ${ }^{20}$ These rates still present an important geographic variation, reaching much higher values in countries alongside the Silk Road, with progressive decline as it moves towards the west.

But even in eastern countries, test sensitivity has declined over the decades (from $64.2 \%$ in the 1970 s to $35.8 \%$ in the first decade of this century in an Iranian center). ${ }^{21}$ Surgical sterilization of the site and use of disposable needles were suggested as possible justifications for this reduction. ${ }^{20}$ However, the cause remains unclear. ${ }^{21}$

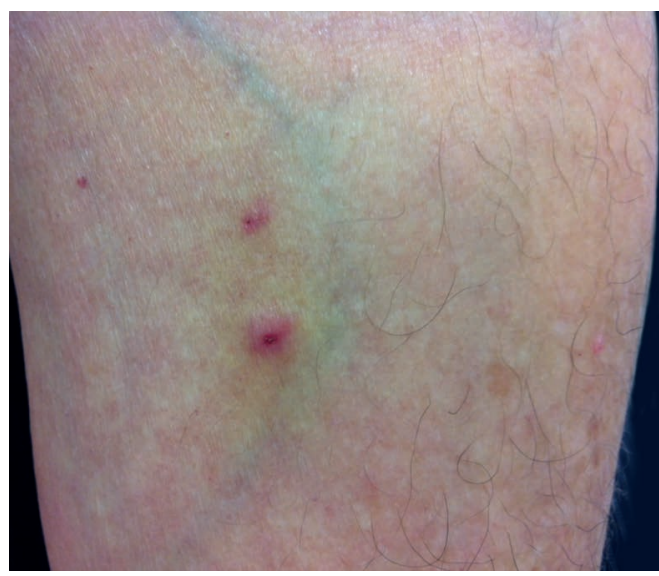

FIGURE 10:

Positive and strongly positive pathergy skin test $(15 \mathrm{~mm})$ in two micropuncture sites on the forearm
Based on studies showing an increase in Streptococcus sanguis in the normal bacterial flora of patients with BD, some authors have proposed the use of the patient's saliva during the pathergy test, in an attempt to enhance the immune response and to increase the test sensitivity.22

A study performed in Brazil showed a $91.3 \%$ positivity rate in 23 patients with a diagnosis of BD. ${ }^{20}$ In this study, the test was performed in four distinct regions of the forearm and, with the aid of clinical and dermoscopic examination, the area with the highest evidence of tissue reaction was biopsied.

\section{OTHER CLINICAL MANIFESTATIONS}

\section{Ocular manifestations}

Ocular disease, more common among men, affects the retina and uvea, occurring in $30-70 \%$ of patients, causing blindness in $25 \%$ of them. It usually appears 2-3 years after oral and/or genital ulcers, but may be the first manifestation of the disease in 10$20 \%$ of cases. It is characterized by episodes of recurrent, bilateral, non-granulomatous chronic uveitis, which affects the anterior, posterior or both segments (panuveitis) of the eye. One-third of the patients may present with hypopyon, or accumulation of pus in the anterior chamber of the eye (Figure 12). Other manifestations include iridocyclitis, keratitis, episcleritis, scleritis, vitritis, vitreous

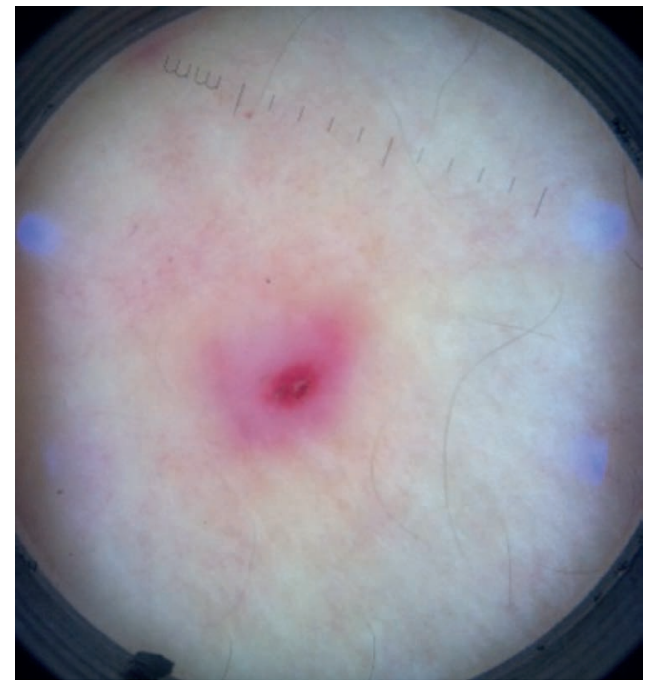

Figure 11 :

Positive pathergy skin test on dermoscopy: erythematous papule surrounded by an erythematous halo and topped by mild exulcerated crusts (X10 magnification)

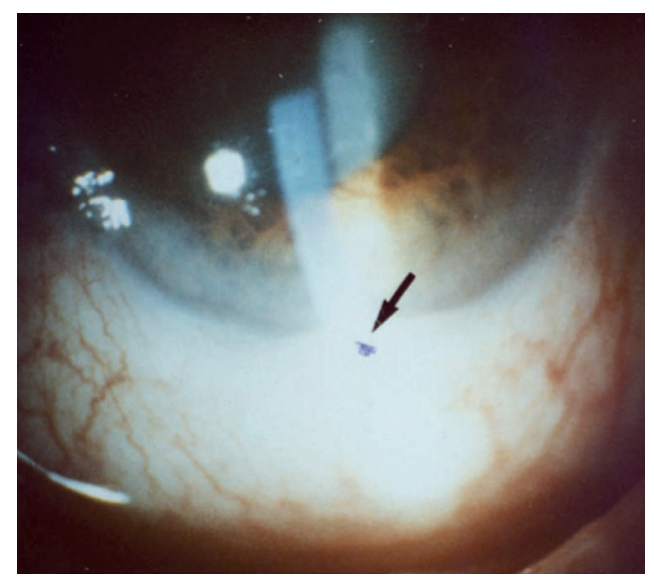

Figure 12:

Hypopyon: accumulation of pus in the anterior chamber of the eye 
hemorrhage, retinal vasculitis, retinal vein occlusion, retinal neovascularization, and optic neuritis. These findings are significantly related to the reduction of visual acuity. ${ }^{1,5,6}$

\section{Neurological manifestations}

Neurological impairment occurs in $5-10 \%$ of the patients, affecting mostly men. It occurs about five years after the onset of the disease mainly affecting the central nervous system and the peripheral nervous system to a lesser extent. This involvement may be parenchymal, non-parenchymal, or both. In the first case, it affects the brainstem and/or basal ganglia, which is linked to a worse prognosis. Non-parenchymal brain disease comprises cerebral venous thrombosis, arterial vasculitis, and aseptic meningitis. Its prognosis is unfavorable in all forms. Magnetic resonance imaging is important even for differential diagnosis with multiple sclerosis. A case series describing 23 children with cerebral venous sinus thrombosis caused by BD suggests its inclusion in the differential diagnosis of children with persistent headache. ${ }^{1,5,6}$

\section{Vascular manifestations}

Deep vein thromboses of the extremities are the most common form of vascular involvement together with recurrent superficial venous thrombosis. Men are more affected than women. Deep vein thrombosis of the extremities occur in $30-40 \%$ of patients, and inferior or superior vena cava thrombosis is reported in $0.2-9 \%$ of cases. Studies with groups of patients with Budd-Chiari syndrome caused by BD revealed the following features: male predilection, younger age, early onset of disease, mainly caused by occlusion of the inferior vena cava, presence of silent cases, increased mortality, rarely associated with portal vein thrombosis, good response to immunosuppressants rather than anticoagulants alone, and poor success of vascular interventions. Pulmonary artery aneurysms are more commonly described in Turkey and rarely in Japan. Since it usually has a silent presentation, certain groups of English surgeons suggest that thoracic aortic imaging should be a procedure for all BD patients. Cardiac involvement includes pericarditis, myocarditis, mitral valve prolapse, intracardiac thrombosis, endomyocardial fibrosis, cardiomyopathy, and coronary artery lesions. A recent meta-anlyzis of nine studies found that subclinical atherosclerosis is increased in BD patients.

\section{Joint manifestations}

Joint involvement is reported in $45-60 \%$ of BD patients and includes arthralgia and non-erosive and non-deforming monoarthritis or polyarthritis. It affects knees, ankles, hips, elbows, wrists with neutrophilic and mononuclear inflammatory synovial infiltrates and thrombosis of small vessels. Anti-inflammatory treatment is generally effective with a good prognosis. Ankylosing spondylitis was described in $10 \%$ of cases by Hatemi et al. Pseudofolliculitis was the manifestation most associated with this involvement. ${ }^{1,5,6}$

\section{Gastrointestinal manifestations}

The gastrointestinal tract is affected in 3-26\% of patients, varying in different populations, being more frequent in Japan than in the Middle East and Mediterranean. Mucosal inflammation and ulceration can occur throughout the gastrointestinal tract, but especially in the ileocecal region where the presence of large oval ulcers can be observed. Differential diagnosis should be made with Crohn's disease. Capsule endoscopy proved to be important for the detection of small intestinal lesions. ${ }^{1.5}$

\section{Miscellaneous}

Some reports have shown a decrease in the reserve of anti-Müllerian hormone in the ovaries, which has not been confirmed by other publications. ${ }^{5}$

Renal impairment is uncommon. In a retrospective study, 16 patients out of 618 were affected. Six had chronic glomerulonephritis, one had tubular acidosis, eight had renal artery stenosis, and one had renal vein thrombosis. ${ }^{6}$

The presence of fatigue in inflammatory diseases has been the object of recent research. Its severity and impact on BD are similar to other diseases such as rheumatoid arthritis, systemic lupus erythematosus, and ankylosing spondylitis. It affects both sexes, with no differences between subgroups with different involved organs, and those with active disease are more affected. Depression, anxiety, and physical dysfunction may be associated.

Suicidal thoughts were more frequent among patients with involvement of other organs than those with mucocutaneous forms, signaling the precaution that should be taken in the care of these patients. $^{6}$

British reports showed occupational changes, requiring work changes in BD patients, mainly due to speech difficulties caused by oral ulcers. ${ }^{6}$

A study performed in Thailand showed increased breast and hematologic cancer among women during the first few years of follow-up. ${ }^{5}$

\section{DIAGNOSTIC CRITERIA}

As there are no pathognomonic laboratory tests, BD diagnosis is based on clinical criteria and on the exclusion of other diseases. Even so, the diagnosis is challenging considering that the symptoms are not concomitant. Sixteen classification and diagnostic criteria were described. The first was proposed by Curth in 1946. It was only in 1969 that two other criteria emerged, which were Hewitt's and Mason \& Barnes' criteria. In 1971, Hewitt revised his criteria. In 1972, new criteria were presented by the Research Committee on BD in Japan. In 1974, Hubault and Hamza, followed by O'Duffy in that same year, gave their contributions. ${ }^{13}$ Despite the existence of these 10 criteria, no consensus had been established yet, so that, in 1990, a group of seven countries, the International Study Group of $\mathrm{BD}$, presented new criteria, which showed high specificity but low sensitivity. As a result, other criteria were proposed, which included Iran traditional criteria (1993), Iran Classification Tree (1993), Dilsen revised criteria (2000), and Korea criteria (2003). In 2004, an international team composed of 27 countries was formed and, two years later, they presented the international criteria for $\mathrm{BD}$, which are employed in Germany, China, and Iran. In 2012, Chapel Hill's 1990 criteria were revised and a new proposal was made. The diagnosis is made by the presence of recurrent oral ulceration (at least three times a year) plus any two of the following: recurrent genital ulceration (leaving scars), ocular lesions (anterior uveitis, posterior uve- 
itis, presence of cells in the vitreous detected in the slit lamp examination, retinal vasculitis), cutaneous lesions (erythema nodosum, pseudofolliculitis or papulopustular lesions, acneiform nodules in patients after adolescence and who are not using corticosteroids), or positive pathergy test results with reading performed 24-48 hours after the test. Despite this, given the diagnostic difficulty, all possible differential diagnoses should be explored.

In 2004, an attempt was made to define a set of clinical criteria that could be used to measure BD activity, thus helping to evaluate the treatments. ${ }^{1}$

There are numerous attempts to validate indexes that can assess disease activity. Currently, the most commonly used instrument is the Behçet's Disease Current Activity Form. However, the only validated score for measuring specific organ involvement is the Oral Ulcer Composite Index. ${ }^{23}$ The multisystemic and episodic character of the disease makes it difficult to assess its activity. Because it has a heterogeneous course that is difficult to evaluate, cutaneous manifestations are common and easy to evaluate. In 2014, Mumcu et al. developed a mucocutaneous activity index that can be used in the management and treatment of BD patients. Although it is a specific score that can help in therapeutic decisions and reduce morbidity, it still lacks validation.

\section{TREATMENT}

The main objective of BD patient treatment is to induce and maintain remission and improve quality of life, preventing irreversible damage and exacerbation of mucocutaneous and articular disease. ${ }^{25,26}$ Its main premise is to eliminate inflammation and comprises the use of immunosuppressive agents in severe, life-threatening, and symptomatic manifestations in mucocutaneous and articular diseases. ${ }^{27}$

As the clinical expression of the disease is heterogeneous, treatment varies according to severity, organ affected, age at onset, disease duration, and frequency of recurrences. ${ }^{4}$

BD treatment is challenging since it is based on fragile studies, mostly consisting of isolated reports or case series, with a few randomized clinical trials. ${ }^{25}$

\section{ORAL ULCERS}

In $\mathrm{BD}$ aphthous oral disease, treatment is aimed at pain relief and reduction of inflammation, with decreased recurrences and duration of ulcers. ${ }^{28}$ The number of controlled studies is still limited. ${ }^{4}$

A recent review of the Cochrane Library has shown the following results for the management of oral ulcers in BD cases: ${ }^{28}$

There were found five placebo-controlled clinical studies comparing topical treatments with placebo for pain management, duration and frequency of ulcers, safety of intervention and adverse effects, two of them with sucralfate solution, two with interferon alpha, and one with cyclosporine A. There was insufficient evidence to support or refute the use of any of these substances in topical treatment of oral ulcers in $\mathrm{BD} .{ }^{28}$

Under the same results, there were found eight placebo-controlled studies comparing systemic treatments to placebo, two of them with colchicine and one with each of the following drugs: acyclovir, thalidomide, rebamipid, corticosteroids, etanercept, and interferon alpha. Again there was insufficient evidence to support or refute the use of any of these substances in the systemic treatment of oral ulcers in BS. ${ }^{28}$

The conclusions of this review are that there is no gold standard treatment for oral ulcers in BD, and several therapies are used in clinical practice. The heterogeneity of the evaluation methodology and of the results impaired the comparisons, in addition to the frequent lack of a wash-out period for cross over studies. ${ }^{28}$

In clinical practice, in addition to advice on oral hygiene, physicians should prescribe the use of antimicrobial mouth rinse (chlorhexidine, tetracycline, triclosan, etc.), silver nitrate, lasers, and topical corticosteroids or pimecrolimus. Patients should also avoid very acidic, salty, or spicy foods. ${ }^{4}$ In addition, associated systemic treatment is suggested, starting with colchicine alone or in combination with oral corticosteroids, followed by azathioprine or thalidomide for refractory cases. ${ }^{4}$

\section{TRADITIONAL TREATMENT FOR BD}

\section{Corticosteroids}

There are no randomized clinical trials reported, but the European League Against Rheumatism (EULAR) recommendation is to use systemic corticosteroids in severe or life-threatening symptoms, such as ocular, vascular, gastrointestinal, or neurological manifestations. ${ }^{25}$ In these circumstances, recommended treatment consists of pulse corticosteroid therapy with methylprednisolone at $1 \mathrm{~g} /$ daily for three days, followed by prednisone $1 \mathrm{mg} / \mathrm{kg} /$ daily at slow weaning. ${ }^{25,29}$

For oral or genital ulcers, topical high-potency corticosteroids may be used during the prodromal stage. For larger or more severe ulcers, triamcinolone injections at the base of the ulcer may be attempted. ${ }^{30}$

Topical ophthalmic corticosteroids may be used in cases of mild anterior uveitis. ${ }^{31}$

\section{Non-steroidal anti-inflammatory drugs}

These drugs are used to treat BD-related arthritis. Indomethacin may be mentioned as an example. ${ }^{25}$

\section{Colchicine}

It is the drug most commonly used for mucocutaneous manifestations in BD, supposedly due to its inhibition of neutrophil chemotaxis. ${ }^{4,25,30}$

Colchicine is effective in the treatment of arthritis and erythema nodosum, and there appears to be a group of patients with oral ulcers who benefit from this treatment, although the results of some randomized clinical trials are disappointing. ${ }^{25-27,29,32}$ Side effects reported are mild, such as gastrointestinal and hair loss. ${ }^{27}$ Oral ulcers can be treated at the oral dose of $0.6-1 \mathrm{mg} 2-3$ times a day..$^{27,30,32}$

\section{Mycophenolate mofetil}

It seems to be an alternative in parenchymal neurologic and pulmonary or ocular BD, but not in cases of mucocutaneous manifestations. However, controlled studies are necessary. ${ }^{25,29,33}$

\section{Dapsone}

Dapsone (DDS) inhibits neutrophil chemotaxis and inter- 
feres with the production of polymorphonuclear oxygen intermediates, conferring tissue protection from injury by auto-oxidation. ${ }^{30,34}$ Other studies suggest that DDS inhibits leukotriene 4 and neutrophil adhesion to interleukin-stimulated endothelial cells $1 .^{35} \mathrm{~A}$ double-blind, placebo-controlled study verified the efficacy of DDS at a dose of $100 \mathrm{mg} /$ daily in the treatment of mucocutaneous lesions in 20 patients. Patients randomly received either placebo or DDS for three months, and then they crossed over to the alternative treatment. Those who used DDS had oral ulcers with less frequency and duration, fewer cutaneous manifestations (such as erythema nodosum and papulopustular lesions) in addition to low prevalence of positive pathergy test results. ${ }^{35}$

\section{Cyclosporin A}

Cyclosporine is mainly indicated for the treatment of ocular impairment in BD. The EULAR, however, recommends that this drug be not used in BD patients with central nervous system involvement, unless an intraocular inflammation is reported, due to the risk of neurotoxicity. ${ }^{25,29}$

Cyclosporin may also be useful in the treatment of acute deep venous thrombosis and in cases of mucocutaneous manifestations, such as oral aphtosis and cutaneous or genital lesions. However, close attention should be paid to its side effects and toxicity. ${ }^{25,30}$

\section{Tacrolimus}

Tacrolimus has similar efficacy to cyclosporin because of its similarities, but no controlled clinical studies of this drug in BD have been published. Open studies have shown some benefit in cases of ocular involvement. ${ }^{25}$

\section{Azathioprine}

The use of azathioprine in ophthalmic disease is recommended by the EULAR. ${ }^{26}$

A randomized controlled clinical study shows its effectiveness in ocular disease control and reduction of a new involvement of the organ. The same study showed decreased development of new genital ulcers, arthritis, and thrombophlebitis, as well as reduced vascular and neurologic impairment in patients treated with azathioprine. ${ }^{27,29}$

Uncontrolled data suggest benefits in the treatment of gastrointestinal and long-term disease in vascular involvement, in addition to neurological, joint and mucocutaneous disease. ${ }^{27,33}$

\section{Cyclophosphamide}

Cyclophosphamide is mainly indicated for parenchymal and large vessel neurological involvement. ${ }^{25,27}$ The EULAR suggests its use in upper vena cava thrombosis or Budd-Chiari syndrome. ${ }^{25,26}$

It is not recommended for ocular disease..$^{25,29}$

\section{Thalidomide}

Although thalidomide is effective in the treatment of orogenital ulcers in BD patients at a dose of $100 \mathrm{mg} /$ daily, several studies report that a maintenance dose is required to prevent recurrences. ${ }^{25,27,30,36}$

Several studies report its use to treat colitis in BD patients at a dose of 100 to $300 \mathrm{mg} /$ daily.
Erythema nodosum lesions worsen during treatment with

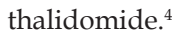

\section{Methotrexate}

Some studies reported its use in patients with ocular involvement or with neurological diseases. ${ }^{25.33}$

\section{Anticoagulants}

There is still no scientific evidence of the benefits of anticoagulants in the treatment of deep venous thrombosis and arterial lesions of BD. Therefore, the EULAR does not recommend the use of these drugs with this indication. However, this subject is still controversial. ${ }^{5,25,26}$

\section{IMMUNOBIOLOGICALS}

\section{Tumor necrosis factor alpha inhibitors}

Refractory ocular involvement remains the primary indication for the use of alpha tumor necrosis factor (TNF-alpha) inhibitors, but successful outcomes of its use in extraocular manifestations have been reported in a growing number of studies. ${ }^{5}$

\section{Infliximab}

Although there are no controlled studies, some reports show the evidence of its efficacy in the treatment of arthritis and ocular, intestinal, neurological, and vascular manifestations of BD..$^{25.37}$

There are numerous case reports of its use in uveoretinitis as monotherapy, usually at a dose of $5 \mathrm{mg} / \mathrm{kg}$ IV every 6-8 weeks. Mild side effects have been reported. Although it has a rapid action, repeated infusions are required. ${ }^{25,27,29}$

There are reports of its use in severe intestinal involvement, without major side effects. ${ }^{25}$

For the treatment of neurological and vascular diseases, as well as for arthritis and mucocutaneous manifestations, reports or case series also show favorable results. ${ }^{25}$

\section{Etanercept}

It is the only TNF-alpha inhibitor evaluated in a randomized controlled clinical trial with efficacy to suppress most mucocutaneous manifestations, decreasing the frequency of aphtous ulcers, papular and pustular lesions, and arthritis, but without suppressing the pathergy reaction. ${ }^{25.27}$

\section{Adalimumab}

Case reports show favorable results in the treatment of ocular disease, ${ }^{38,39}$ lower-limb and genital ulcerations, cerebral vasculitis, and gastrointestinal disease. ${ }^{25.38-40}$

\section{Rituximab}

Some case reports suggest its use in the treatment of ocular disease. ${ }^{25}$

\section{Other immunobiologicals}

Interleukin 1 inhibitors

So far, three inhibitors of interleukin-1 (anti-IL1) have been tested in BD: ${ }^{5.41}$

a) Gevokizumab recombinant humanized anti-IL1 beta

There are reports of its use in the treatment of ocular disease..$^{5.25}$

b) canakinumab: monoclonal anti-IL1 beta antibody

There are case reports of its use in ocular inflammation, resistant fever, recurrent oral and genital aphtosis, and in gastrointes- 
tinal, neurological and vascular disease of BD. 5,25,33

c) Anakinra IL1 receptor antagonist

Case reports of treatment of patients with recurrent fever, genital and oral ulcers, and intestinal involvement. Reactions were observed only at the injection sites, with refractory mucocutaneous lesions in some cases. ${ }^{5,25,42}$

A multicenter study evaluated the efficacy of anakinra and canakinumab in a cohort of 30 patients and showed efficacy and safety in their use, with no serious adverse effects but reactions at injection sites. Anti-IL1 beta has the advantage of not presenting the risk of tuberculosis reactivation, unlike TNF alpha inhibitors. ${ }^{43} \mathrm{~Pa}-$ tients with low response to anakinra initially showed good response with increasing doses. Switching to canakinumab after failure of anakinra therapy was also reported as a good option. ${ }^{43}$

\section{INTERFERON ALFA}

Interferon alfa (IFN alpha) showed to be effective in treating mucocutaneous manifestations (a randomized controlled clinical study), joint manifestations (a systematic review), ocular manifestations (uncontrolled prospective study, several open and retrospective studies) and neurological manifestations (case reports) of BD. It is administered subcutaneously and should not be used in conjunction with azathioprine, at the risk of myelosuppression, or in patients with a history of depression or psychosis, unless there is no other therapy available. ${ }^{26,45}$

\section{APREMILAST}

It is an inhibitor of phosphodiesterase 4 with oral administration. A double-blind controlled study showed its effectiveness in decreasing oral ulcers in patients with $\mathrm{BD}^{25,33,46}$ Of the 55 patients treated with this drug, one reported reversible bilateral paralysis of the lower limbs, diagnosed as a conversion syndrome, and another reported anal fissure with hemorrhoids after diarrhea. ${ }^{46}$

\section{OTHER THERAPIES}

Reamipid is an amino acid analog of $2(1 \mathrm{H})$-quinolinone used in the treatment of duodenal ulcers, which acts by reducing oxygen radicals, increasing the production of prostaglandins in the ulcerated mucosa, thus accelerating the healing process. The recommended dose is $100 \mathrm{mg}$ three times a day for two months. There are still no controlled studies of its use in BD. Although rarely used, it is an alternative in the management of oral ulcer pain in patients with BD. . $^{2,27,47}$

There have been reports of the use of pentoxifylline for oral ulcers, with a better response if associated with colchicine. It is generally used at a dose of $400 \mathrm{mg}$ three times a day. ${ }^{30}$

Topical anesthetics such as locally applied viscous lidocaine may be used to relieve pain in oral lesions. Topical granulocyte colony stimulating factor can be used for the treatment of mucocutaneous lesions. ${ }^{25.30}$

Sucralfate has the function of inducing the proliferation of dermal fibroblasts and the formation of granulation tissue, enhancing the binding of growth factors (which improves healing) and forming a protective barrier by binding to the ulcerated tissue. The dose used is $5 \mathrm{ml}$ four times a day as an oral rinse, or topical application to genital lesions. ${ }^{30.48}$

There is a report of the use of topical pimecrolimus associated with oral colchicine showing the same efficacy of the isolated systemic drug, but with greater pain relief in genital lesions. ${ }^{49}$

New treatments with alemtuzumab have been investigated for mucocutaneous, ocular, vascular, and neurological diseases..$^{25.33}$

Hematopoietic stem cell transplantation has been studied for severe diseases unresponsive to other treatments, as well as azacitidine for oral and intestinal ulcerations, due to its immunomodulatory effect. ${ }^{33}$

\section{CONCLUSION}

Behçet disease is a heterogeneous and yet intriguing disease. Despite the remarkable progress in research, many gaps need to be fulfilled. New knowledge regarding its immunopathogenesis, genetics, and epidemiology will greatly help in the development of laboratory tests, diagnostic criteria, activity indexes, and especially in the choice of the best treatment.

The use of interleukin inhibitors appears to be hopeful. The involvement of IL-17, IL-21, and TGF beta in its pathogenesis, as discussed in this study, leads to therapies that would target these cytokines. In this context, IL-21 blockers would be indicated, since this block would restore balance between Th17 and T-reg cells. In addition, the regulatory action of anti-inflammatory cytokines, such as TGF beta, makes the use of apremilast promising. $\left.{ }^{1}\right]$ 


\section{REFERENCES}

1. Zeidan MJ, Saadoun D, Garrido M, Klatzmann D, Six A, Cacoub P. Behçet's disease physiopathology: a contemporary review. Auto Immun Highlights. 2016;7:4.

2. Davatchi F, Sadeghi Abdollahi B, Chams-Davatchi C, Shahram F, Ghodsi Z, Nadji $A$,et al. Impact of the positive pathergy test on the performance of classification/ diagnosis criteria for Behcet's disease. Mod Rheumatol. 2013;23:125-32.

3. Scherrer M. Doença de Behçet: um enigma oriental. An Bras Dermatol. 1994:69:323- -6 .

4. Alpsoy E. Behçet's disease: A comprehensive review with a focus on epidemiology, etiology and clinical features, and management of mucocutaneous lesions. $J$ Dermatol. 2016;43:620-32

5. Hatemi G, Seyahi E, Fresko I, Talarico R, Hamuryudan V. One year in review 2016: Behçet's syndrome. Clin Exp Rheumatol. 2016;34:10-22.

6. Hatemi G, Seyahi E, Fresko I, Talarico R, Hamuryudan V. Behçet's syndrome: a critical digest of the 2014ᄀ-2015 literature. Clin Exp Rheumatol. 2015;33:S3-14.

7. Hatemi G, Karatemiz G, Yazici H. Behçet's disease: an MHC-I-opathy? Clin Exp Rheumatol. 2017;35:5.

8. Varol A, Seifert 0 , Anderson CD. The skin pathergy test: innately useful? Arch Dermatol Res. 2010;302:155-68.

9. Lee S, Bang D, Lee E, Sohn S. Behçet's Disease: a guide to its clinical understanding. New York: Springer-Velag; 2001

10. Baş Y, Seçkin HY, Kalkan G, Takcı Z, Önder Y, Çıtıl R,et al. Investigation of Behçet's Disease and Recurrent Aphthous Stomatitis Frequency: The Highest Prevalence in Turkey. Balkan Balkan Med J. 2016;33:390-5

11. Alpsoy E, Zouboulis CC, Ehrlich GE.Mucocutaneous lesions of Behcet's disease. Yonsei Med J. 2007:48:573-85

12. Ergun T, Gürbüz O, Dogusoy G, Mat C, Yazici H.Histopathologic features of the spontaneous pustular lesions of Behçet's syndrome. Int J Dermatol. 1998;37:194-6.

13. de Carvalho V0, Abagge KT, Giraldi S, Kamoi TO, Assahide MK, Fillus Neto J, et al. Behçet disease in a child - emphasis on cutaneous manifestations. Pediatr Dermatol. 2007;24:E57-62.

14. Kim B, LeBoit PE. Histopathologic features of erythema nodosum-like lesions in Behçet disease: a comparison with erythema nodosum focusing on the role of vasculitis. Am J Dermatopathol. 2000;22:379-90.

15. Lee ES, Bang D, Lee S. Dermatologic manifestation of Behçet's disease. Yonsei Med J. 1997;38:380-9.

16. Azizlerli G, Ozarmağan G, Ovül C, Sarica R, Mustafa SO.A new kind of skin lesion in Behçet's disease: extragenital ulcerations. Acta Derm Venereol. 1992;72:286.

17. Treudler R, Orfanos CE, Zouboulis CC. Twenty-eight cases of juvenile -onset Adamantiades $\neg$ Behçet disease in Germany. Dermatology. 1999;199:15-9.

18. Karadoğan SK, Başkan EB, Alkan G, Saricaoğlu H, Tunali S. Generalized Sweet syndrome lesions associated with Behçet disease: a true association or simply co-morbidity? Am J Clin Dermatol. 2009;10:331-5.

19. Schreiner DT, Jorizzo JL. Behçet's disease and complex aphthosis. Dermatol Clin 1987;5:769-78

20. Scherrer MA, de Castro LP, Rocha VB, Pacheco L. Dermatoscopia no teste cutâneo da patergia: série de casos de pacientes com suspeita de Doença de Behçet. Rev Bras Reumatol. 2014;54:494-8.

21. Davatchi F, Chams-Davatchi C, Ghodsi Z, Shahram F, Nadji A, Shams H,et al. Diagnostic value of pathergy test in Behcet's disease according to the change of incidence over the time. Clin Rheumatol. 2011;30:1151-5.

22. Kaneko F, Togashi A, Nomura E, Nakamura K.A New Diagnostic Way for Behcet's Disease: Skin Prick with Self -Saliva. Genet Res Int. 2014;2014:581468.

23. Hatemi G, Seyahi E, Fresko I, Talarico R, Hamuryudan V. Behçet's syndrome: a critical digest of the 2013 2014 literature. Clin Exp Rheumatol. 2014;32:S112-22.

24. Mumcu G, Inanc N, Taze A, Ergun T, Direskeneli H.A new Mucocutaneous Activity Index for Behçet's disease. Clin Exp Rheumatol. 2014;32:S80-6

25. Saleh Z, Arayssi T. Update on the therapy of Behçet disease. Ther Adv Chronic Dis. 2014:5:112-34

26. Hatemi G, Silman A, Bang D, Bodaghi B, Chamberlain AM, Gul A, et al. EULAR recommendations for the management of Behçet disease. Ann Rheum Dis. 2008:67:1656-62.

27. Hatemi G, Silman A, Bang D, Bodaghi B, Chamberlain AM, Gul A, et al. Management of Behçet disease: a systematic literature review for the European League Against Rheumatism evidence-based recommendations for the management of Behçet disease. Ann Rheum Dis. 2009:68:1528-34.

28. Taylor J, Glenny AM, Walsh T, Brocklehurst P, Riley P, Gorodkin R, et al. Interventions for the management of oral ulcers in Behçet's disease. Cochrane Database Syst Rev. 2014;25:CD011018.
29. Mazzoccoli G, Matarangolo A, Rubino R, Inglese M, De Cata A. Behçet syndrome: from pathogenesis to novel therapies. Clin Exp Med. 2016;16:1-12.

30. Lin P, Liang G. Behçet disease: recommendation for clinical management of mucocutaneous lesions. J Clin Rheumatol. 2006;12:282-6.

31. Wakefield D, Cunningham ET Jr, Tugal-Tutkun I, Khairallah M, Ohno S, Zierhut M. Controversies in Behçet disease. Ocul Immunol Inflamm. 2012;20:6-11.

32. Davatchi F, Sadeghi Abdollahi B, Tehrani Banihashemi A, Shahram F, Nadji A, Shams $\mathrm{H}$,et al. Colchicine versus placebo in Behçet's disease: randomized, double-blind, controlled crossover trial. Mod Rheumatol. 2009;19:542-9.

33. Vitale A, Rigante D, Lopalco G, Emmi G, Bianco MT, Galeazzi M,et al. New therapeutic solutions for Behçet's syndrome. Expert Opin Investig Drugs. 2016;25:827-40.

34. Miyachi Y, Niwa Y. Effects of potassium iodide, colchicine and dapsone on the generation of polymorphonuclear leukocyte $\neg$ derived oxygen intermediates. $\mathrm{Br} \mathrm{J}$ Dermatol. 1982;107:209-14.

35. Sharquie KE, Najim RA, Abu-Raghif AR.Dapsone in Behçet's disease: a doubleblind, placebo $\neg$ controlled, cross $\neg$ over study. J Dermatol. 2002;29:267-79.

36. Hamuryudan V1, Mat C, Saip S, Ozyazgan $Y$, Siva A, Yurdakul S, et al. Thalidomide in the treatment of the mucocutaneous lesions of the Behçet syndrome. A randomized, double-blind, placebo-controlled trial. Ann Intern Med. 1998; $128: 443-50$

37. Hazirolan D, Stübiger N, Pleyer U. Light on the horizont: biologicals in Behçet uveitis. Acta Ophthalmol. 2013;91:297-306.

38. Bawazeer A, Raffa LH, Nizamuddin SH. Clinical experience with adalimumab in the treatment of ocular Behçet disease. Ocul Immunol Inflamm. 2010;18:226-32.

39. Fabiani C, Vitale A, Emmi G, Vannozzi L, Lopalco G, Guerriero S,et al. Efficacy and safety of adalimumab in Behçet's disease $\neg$ related uveitis: a multicenter retrospective observational study. Clin Rheumatol. 2017;36:183-189.

40. Vitale A, Emmi G, Lopalco G, Gentileschi S, Silvestri E, Fabiani C,et al. Adalimumab effectiveness in Behçet's disease: short and long-term data from a multicenter retrospective observational study. Clin Rheumatol. 2017;36:451-5.

41. Vitale A, Rigante D, Lopalco G, Selmi C, Galeazzi M, lannone F,et al. Interleukin $\neg 1$ Inhibition in Behçet's disease. Isr Med Assoc J. 2016;18:171-6.

42. Cantarini L, Vitale A, Scalini P, Dinarello CA, Rigante D, Franceschini Ret al. Anakinra treatment in drug-resistant Behcet's disease: a case series. Clin Rheumatol. 2015:34:1293-301.

43. Emmi G, Talarico R, Lopalco G, Cimaz R, Cantini F, Viapiana 0,et al. Efficacy and safety profile of anti-interleukin-1 treatment in Behçet's disease: a multicenter retrospective study. Clin Rheumatol. 2016;35:1281-6.

44. Alpsoy E, Durusoy C, Yilmaz E, Ozgurel Y, Ermis O, Yazar S, et al. Interferon alfa$2 \mathrm{a}$ in the treatment of Behçet disease: a randomized placebo $\neg$ controlled and double $\neg$ blind study. Arch Dermatol. 2002;138:467-71.

45. Kötter I, Günaydin I, Zierhut M, Stübiger N. The use of interferon alpha in Behçet disease: review of the literature. Semin Arthritis Rheum. 2004;33:320-35.

46. Hatemi G, Melikoglu M, Tunc R, Korkmaz C, Turgut Ozturk B, Mat C,et al. Apremilast for Behçet's syndrome - a phase 2, placebo-controlled study. N Engl J Med. 2015;372:1510-8.

47. Kudur MH, Hulmani M. Rebamipide: A Novel Agent in the Treatment of Recurrent Aphthous Ulcer and Behcet's Syndrome. Indian J Dermatol. 2013;58:352-4.

48. Alpsoy E, Er H, Durusoy C, Yilmaz E.The use of sucralfate suspension in the treatment of oral and genital ulceration of Behçet disease: a randomized, placebocontrolled, double-blind study. Arch Dermatol. 1999;135:529-32.

49. Köse 0, Dinç A, Simşek I. Randomized trial of pimecrolimus cream plus colchicine tablets versus colchicine tablets in the treatment of genital ulcers in Behçet's disease. Dermatology. 2009;218:140-5.

How to cite this article: Scherrer MAR, Rocha VB, Garcia LC. Behçet's disease: review with emphasis on dermatological aspects. An Bras Dermatol. 2017;92(4):452-64. 


\section{QUESTIONS}

1. Behçet's disease (BD) is characterized by:

a) predictable attacks of acute inflammation

b) almost totally affecting the eyes, evolving to blindness

c) the ability to affect almost every vascularized area of the body

d) all of the above

2. Regarding BD epidemiology, it is INCORRECT to state that:

a) There is a close correlation between the distribution of HLA-B51 and the prevalence of the disease

b) the frequency of HLA-B51 in the Silk Road area is 20$25 \%$ among the general population

c) the frequency of HLA-B51 among patients in the Silk Road area is $50-80 \%$

d) the disease is primarily geographic and not hereditary, as there is no environmental influence on its susceptibility

3. Check the region where the prevalence of $\mathrm{BD}$ is highest:
a) West
b) Turkey
c) The United Kingdom
d) Japan and Africa

4. Mark the INCORRECT statement regarding BD:

a) men have a worse prognosis due to the greater frequency of vital organs affected

b) gender does not influence the evolution of the disease

c) more severe forms are observed when the disease affects younger individuals

d) children can also be affected by the disease

5. The following aspects evidence the genetic influence on susceptibility to BD, EXCEPT:
a) familial aggregation
b) peculiar geographical distribution
c) correlation with HLA-B51
d) polymorphisms of genes that control apoptosis

6. Regarding the genetics of $\mathrm{BD}$, it is INCORRECT to state that:

a) the association with HLA-B51 appears to be important in eosinophilic activation

b) studies suggest association with HLA B15, B27, B57, and A26

c) HLA-B49 and A03 appear to be protective

d) significant genetic association was found with SNP rs116799036

7. Regarding the pathogenesis of $\mathrm{BD}$, it is CORRECT to state that:

a) there is an interaction between innate and adaptive im- munity, but not with environmental factors

b) infectious agents such as fungi and viruses have been investigated, with conclusive results

c) improvement in oral health does not alter the prognosis

d) patients have a less diverse microbial structure than controls, with Hemophilus parainfluenza being the most abundant bacteria

8. Regarding the pathogenesis of $\mathrm{BD}$, it is INCORRECT to state that:

a) peripheral blood of patients contains IL12

b) there is involvement of the Th1 cell mediated response

c) a Chinese group showed high reactivity of $\operatorname{IgM}$ against endothelial cell autoantigens

d) there is dysbiosis of the gut microbiota with a significant reduction of butyrate production in BD patients

\section{Check the CORRECT statement regarding oral ulcers in} BD:

a) they are present in $50 \%$ of cases

b) they constitute the initial manifestation in $20 \%$ of cases

c) they precede the subsequent manifestations in 1-2 years

d) ) they are painful

10. Still in relation to oral ulcers, it is INCORRECT to state that:

a) they arise in outbreaks at an average of 2.8 times a year

b) they have well-defined borders

c) they reveal the formation of a yellowish or grayish pseudomembrane

d) they are localized in the non-keratinized portion of the oral mucosa

11. The genital ulcers in $\mathrm{BD}$ :

a) are different from oral ulcers in appearance and course

b) are more recurrent

c) have a lower tendency for scar formation

d) may exhibit necrotic borders

12. Regarding the mucocutaneous manifestations of $\mathrm{BD}$, it can be stated that:

a) in men, the most affected site in the genital region is the penis

b) vaginal and cervical ulcers may be oligosymptomatic

c) in women, the most frequently affected region is the labia minora

d) there are specific cutaneous lesions of $\mathrm{BD}$

13. Regarding cutaneous lesions in $\mathrm{BD}$, it can be stated that: a) they do not contribute to the diagnosis of the disease

b) different types may include erythema nodosum, papulopustular, thrombophlebitis, ulcers and vasculitis 
c) vasculitides are always neutrophilic

d) erythema nodosum-like lesions occur in two thirds of patients and always develop with ulceration

\section{In relation to pathergy, it can be stated that:}

a) it was described in 1945

b) it is defined as an altered state of the tissue response to minimal trauma

c) reflects an exacerbated response of the acquired immune system

d) sensitivity to skin pathergy tests has been increasing over the years

15. In relation to ocular manifestations, the following statements are correct, EXCEPT:

a) $75 \%$ of patients develop blindness

b) they are characterized by episodes of recurrent chronic uveitis

c) one-third of the patients may present with hypopyon

d) retinal vasculitis, retinal vein occlusion, and retinal neovascularization may occur

16. Regarding neurological manifestations, the following statements are correct, EXCEPT:

a) they equally affect the central and peripheral nervous systems

b) brainstem and basal ganglia can be affected

c) cerebral venous thrombosis, arterial vasculitis, and aseptic meningitis may occur

d) a differential diagnosis should be made with multiple sclerosis

17. Regarding vascular manifestations, the following statements are correct, EXCEPT:

a) the occurrence of Budd-Chiari syndrome is rarely associated with portal vein thrombosis

b) pulmonary artery aneurysms occur mainly in Turkey

c) cardiac involvement may cause pericarditis, myocarditis, and coronary artery lesions

d) vascular lesions show a good response to anticoagulants and vascular interventions

18. Regarding the diagnosis of $\mathrm{BD}$, it can be stated that:

a) there are several diagnostic criteria with high sensitivity and specificity

b) the presence of vascular lesions is an important criterion, since BD is a systemic vasculitis

c) pathergy skin test has little value, since it is infrequent

d) its diagnosis is challenging, insofar as the symptoms are not concomitant

19. In relation to the treatment of oral ulcers in $B D$, it is INCORRECT to state that: a) colchicine is considered the gold standard of treatment

b) for the prodromal phase, topical and high-potency corticosteroids can be used

c) for major ulcers, corticosteroid injections can be used at the base of the lesion

d) as oral treatment, colchicine alone or associated with oral corticosteroids may be used, in addition to dapsone and thalidomide

\section{Mark the CORRECT statement:}

a) thalidomide is used with great efficacy in the treatment of erythema nodosum lesions

b) dapsone seems to improve oral ulcers, erythema nodosum, and papulopustular lesions

c) meloxicam is the main anti-inflammatory used in joint BD

d) cyclophosphamide is used in the treatment of ocular disease

\section{Answer key}

Cutaneous mucormycosis. An Bras Dermatol. 2017;92(3):304-11

\begin{tabular}{llll}
\hline & & & \\
1.B & 6.C & $11 . \mathrm{C}$ & $16 . \mathrm{B}$ \\
2.A & $7 . \mathrm{D}$ & $12 . \mathrm{B}$ & $17 . \mathrm{D}$ \\
3.A & 8.B & $13 . \mathrm{A}$ & $18 . \mathrm{A}$ \\
$4 . \mathrm{B}$ & $9 . \mathrm{D}$ & $14 . \mathrm{B}$ & $19 . \mathrm{B}$ \\
5.D & $10 . \mathrm{A}$ & $15 . \mathrm{D}$ & $20 . \mathrm{C}$ \\
\hline
\end{tabular}

\section{Papers}

Information for all members: The EMC-D questionnaire is now available at the homepage of the Brazilian Annals of

Dermatology: www.anaisdedermatologia.org.br. The dead-

line for completing the questionnaire is 30 days from the date

of online publication. 